\title{
A new phenotype of mitochondrial disease characterized by familial late-onset predominant axial myopathy and encephalopathy
}

\author{
Yusuke Sakiyama $\cdot$ Yuji Okamoto $\cdot$ Itsuro Higuchi $\cdot$ Yukie Inamori · \\ Yoko Sangatsuda $\cdot$ Kumiko Michizono - Osamu Watanabe · Hideyuki Hatakeyama • \\ Yu-ichi Goto $\cdot$ Kimiyoshi Arimura $\cdot$ Hiroshi Takashima
}

Received: 20 January 2011/Revised: 11 March 2011/Accepted: 11 March 2011/Published online: 22 March 2011

(C) The Author(s) 2011. This article is published with open access at Springerlink.com

\begin{abstract}
Axial myopathy is a rare neuromuscular disease that is characterized by paraspinal muscle atrophy and abnormal posture, most notably camptocormia (also known as bent spine). The genetic cause of familial axial myopathy is unknown. Described here are the clinical features and cause of late-onset predominant axial myopathy and encephalopathy. A 73-year-old woman presented with a 10 -year history of severe paraspinal muscle atrophy and cerebellar ataxia. Her 84-year-old sister also developed late-onset paraspinal muscle atrophy and generalized seizures with encephalopathy. Computed tomography showed severe atrophy and fatty degeneration of their paraspinal muscles. Their mother and maternal aunt also developed bent spines. The existence of many ragged-red fibers and cytochrome $c$ oxidase-negative fibers in the biceps brachii muscle of the proband indicated a mitochondrial abnormality. No significant abnormalities were observed in the respiratory chain enzyme activities; however, the activities
\end{abstract}

Y. Sakiyama · Y. Okamoto - I. Higuchi · Y. Inamori ·

K. Michizono $\cdot$ O. Watanabe $\cdot$ H. Takashima $(\bowtie)$

Department of Neurology and Geriatrics, Kagoshima University

Graduate School of Medical and Dental Sciences,

8-35-1 Sakuragaoka, Kagoshima City,

Kagoshima 890-8520, Japan

e-mail: thiroshi@m3.kufm.kagoshima-u.ac.jp

\section{Y. Sangatsuda}

Department of Psychiatry, Kagoshima University Graduate

School of Medical and Dental Sciences, Kagoshima, Japan

H. Hatakeyama · Y. Goto

Department of Mental Retardation and Birth Defect Research, National Institute of Neuroscience,

National Center of Neurology and Psychiatry, Tokyo, Japan

K. Arimura

Division of Neurology, Okatsu Hospital, Kagoshima, Japan of complexes I and IV were relatively low compared with the activities of other complexes. Sequence analysis of the mitochondrial DNA from the muscle revealed a novel heteroplasmic mutation $(\mathrm{m} .602 \mathrm{C}>\mathrm{T})$ in the mitochondrial tRNA $^{\text {Phe }}$ gene. This familial case of late-onset predominant axial myopathy and encephalopathy may represent a new clinical phenotype of a mitochondrial disease.

Keywords Mitochondrial disease .

Predominant axial myopathy · Encephalopathy ·

Late-onset · Familial case

\section{Introduction}

Camptocormia, a term coined by Souques and RosanoffSaloff from two Greek words (kamptos meaning bent and kormos meaning trunk), is characterized by involuntary trunk flexion in the erect position that disappears in the supine position. Camptocormia was initially described as a hysterical phenomenon that occurred in male soldiers during World Wars I and II $[1,16]$. However, in the last 20 years camptocormia has been reported to be present with various organic diseases, including muscular dystrophies, inflammatory myopathies, dystonia, amyotrophic lateral sclerosis, myasthenia gravis, paraneoplastic syndrome, Parkinson's disease, multiple system atrophy, and spinal deformities, as well as in an idiopathic form. Camptocormia is also referred to as "bent spine syndrome" $[1,32]$.

Axial myopathy has been described as the selective involvement of the paraspinal muscles in camptocormia or dropped head. Axial myopathy has heterogeneous etiologies, including primary and various other neuromuscular disorders. Primary axial myopathy is characterized by the 
insidious and progressive weakness of the extensor muscles of the spine, normal or slightly elevated serum creatine kinase (CK) levels, and a myogenic pattern on electromyography in the elderly. Muscle biopsies show nonspecific myopathic changes with fibrosis, fatty replacement, and variations in fiber size. In addition, some ragged-red fibers and complex I and III deficiencies have been observed; these findings are considered to be the agerelated accumulation of various mitochondrial abnormalities [21, 31].

Some cases of autosomal dominant inheritance patterns of familial primary axial myopathy were reported several years ago; however, the genetic analyses that were used have not been described [31]. Recently, a novel heterozygous dominant mutation in the skeletal muscle ryanodine receptor gene was identified in the central cores of muscle biopsy specimens that were excised from sporadic cases of axial myopathy [15]. Furthermore, facioscapulohumeral muscular dystrophy with isolated axial myopathy has also been reported [19]. Five cases of axial myopathy that were associated with mitochondrial dysfunction have been previously reported; however, no familial cases of mitochondrial gene mutation have been reported $[8,11,28,30,32]$.

In this paper, we have reported about a mitochondrial disease that is characterized by familial late-onset predominant axial myopathy and encephalopathy. In addition, the pathogenicity of a novel, familial, mitochondrial tRNA gene mutation is discussed.

\section{Methods}

\section{Subjects}

\section{Patient 1}

A 73-year-old woman (Fig. 1, III-8) presenting with abnormal posture and gait disturbance. Since the age of 63, the patient had a slight stooping posture and a pushed-out waist. At 68 years of age, she started using a walking stick because of her unstable gait. She was diagnosed with hypothyroidism by her family physician and administrated with $25 \mu \mathrm{g}$ /day levothyroxine; however, her symptoms did not improve. At 70 years of age, it gradually became more difficult for her to climb the stairs. At 71 years of age, she was admitted to another hospital. Doctors suspected myopathy because of elevated serum CK levels. She visited our hospital presenting with prominent paraspinal muscle atrophy and mild proximal weakness of limbs. Hypothyroidism-related myopathy was suspected in her, and hence, the levothyroxine dose was increased to $50 \mu \mathrm{g} / \mathrm{day}$; however, her symptoms did not improve. She had a family history of bent spine, i.e., in her elder sister (patient 2,
Fig. 1, III-5), mother (Fig. 1, II-3), and maternal aunt (Fig. 1, II-4). Physical examination on arrival revealed a marked atrophy of the paraspinal muscles and abnormal posture (Fig. 2a, b). She also presented with right ptosis, dysarthria, bilateral cataracts, and hearing loss. Her eye movements were normal. But there was moderate weakness of the neck flexion and mild weakness of the proximal limb muscles. Tendon reflexes were symmetrical, and Babinski's sign was absent. She had poor balance with tandem gait without limb ataxia. Sensory systems were intact and Romberg's sign was negative. She scored poorly on the attention and calculation tests that are a part of the Mini-Mental State Examination (score: 25 points).

Laboratory data were as follows: serum CK level was 290 IU/1 (normal range 45-163 IU/1), resting blood and cerebrospinal fluid (CSF) lactate levels were normal, thyroid-stimulating hormone levels were slightly low at $0.47 \mu \mathrm{IU} / \mathrm{ml}$ (normal range $0.5-5.0 \mu \mathrm{IU} / \mathrm{ml}$ ). Under the administration of $50 \mu \mathrm{g} /$ day levothyroxine; antithyroglobulin antibody levels were high at $7.0 \mathrm{U} / \mathrm{ml}$ (normal range $<0.3 \mathrm{U} / \mathrm{ml}$ ), antithyroid peroxidase antibody levels were high at $46.5 \mathrm{U} / \mathrm{ml}$ (normal range $<0.3 \mathrm{U} / \mathrm{ml}$ ), rheumatoid factor levels were high at $152.3 \mathrm{IU} / \mathrm{ml}$ (normal value $<15.0 \mathrm{IU} / \mathrm{ml}$ ), antinuclear antibody levels were mildly elevated (titer of 1:80). Autoimmune analyses, including anti-Jo-1, anti-RNP, anti-SS-A, and anti-SS-B, were negative. The oral glucose tolerance test $(75 \mathrm{~g})$ was within normal limits, but Holter monitoring revealed high-frequency premature contractions. Pure-tone audiometry indicated sensorineural and high-frequency hearing loss.

Needle electromyographic findings of the biceps brachii and rectus femoris muscles indicated mild myopathic features. Computed tomography (CT) of the thoracic spinal nerve 10 (T10) revealed severe atrophy and fatty degeneration of the paraspinal muscles (Fig. 2c). Brain magnetic

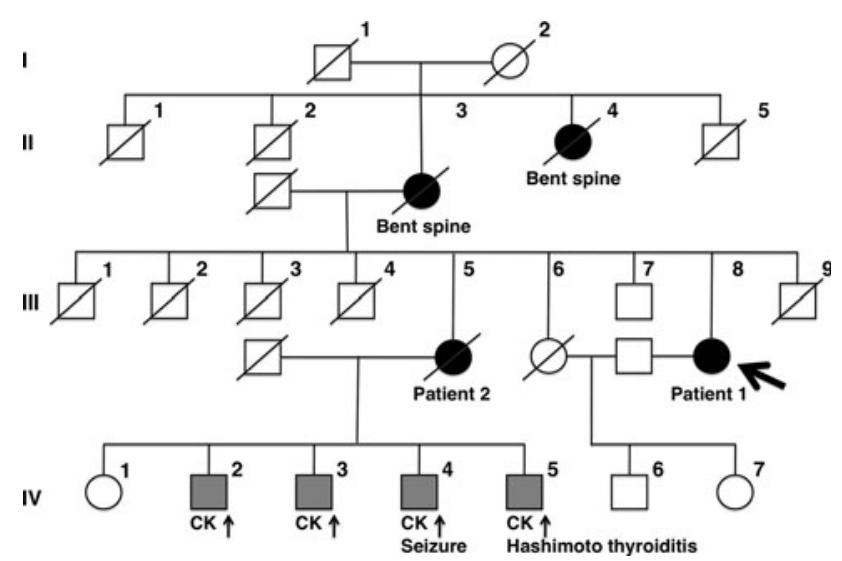

Fig. 1 Pedigree of the family. The arrow indicates the proband. The affected individuals are represented by the solid black symbols; open symbols represent healthy individuals. Gray symbols indicate individuals with elevated CK levels 

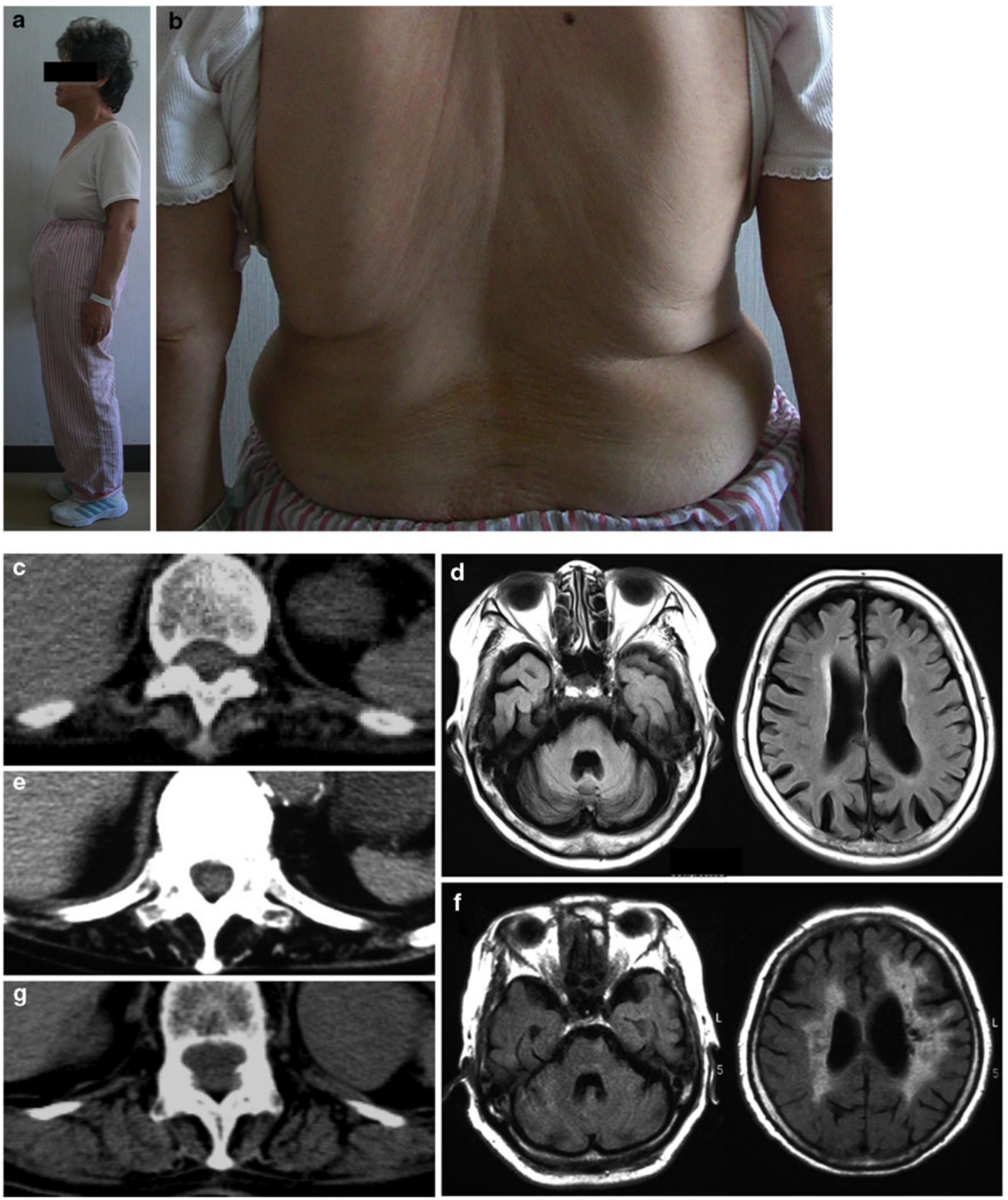

Fig. 2 a The full-length figure indicates the posture of patient 1 showing her pushed-out waist. b The dorsal view shows the marked atrophy of the paraspinal muscles in patient 1 . CT of T10 of $\mathbf{c}$ patient 1 (age 71), e patient 2 (age 82), and $\mathbf{g}$ a healthy female (age 74) reveals the profound atrophy of the paraspinal muscles in $\mathbf{c}$ patient 1

resonance imaging (MRI) with fluid-attenuated inversion recovery imaging showed moderate cerebellar and temporo-parieto-occipital lobe atrophy (Fig. 2d). MR spectroscopy revealed the absence of increased lactate peaks. 123I-IMP single photon emission CT revealed hypoperfusion that was indicative of atrophic brain lesions. and e patient 2, but not in $\mathbf{g}$ the healthy female. Brain MRI studies revealed several differences between the patients 1 and 2. d Axial FLAIR images of patient 1 show moderate cerebellar atrophy and some cerebral cortical atrophy. $f$ The same images of patient 2 revealing hyperintense lesions around the white matter

\section{Patient 2}

The elder sister of patient 1 was an 84-year-old woman with a stooping posture presenting with tremors since the age of 60 . In her 70 s she started walking with the aid of a walking stick. At 82 years of age, she was hospitalized for 
generalized seizures and disturbed consciousness. CT of T10 revealed severe atrophy and fatty degeneration of the paraspinal muscles (Fig. 2e). Brain MRI revealed hyperintense lesions around the white matter (Fig. 2f); elevated serum and CSF lactate levels were also noted at this time. The mitochondrial DNA analysis of the lymphocytes did not indicate MELAS (m.3243A $>$ G) or MERRF (m.8344A $>\mathrm{G})$ mutations. The patient's condition remained undiagnosed and she died at the age of 84 . CK levels in all her four sons were found to be elevated and her third son was diagnosed with epilepsy. She and her fourth son had also been previously diagnosed with Hashimoto thyroiditis (Fig. 1).

Patient 1 was examined using pathological, biochemical, and genetic analyses. The Institutional Review Board of Kagoshima University approved this study. Patient 1 gave the written and informed consent for her participation in this study.

\section{Histochemical and immunohistochemical studies}

Frozen biopsies of the biceps brachii muscle specimens were obtained from patient 1 . The specimens were sliced into $8 \mu \mathrm{m}$ sections and placed on aminosilane-coated slides. Histochemical and immunohistochemical procedures were performed as previously described [13].

\section{Biochemical studies}

Enzyme activity levels, blue native polyacrylamide gel electrophoresis (BN-PAGE), and other biochemical measurements of the frozen muscle specimens from patient 1 were performed as previously described $[6,33,36]$.

\section{Mitochondrial DNA analysis}

In case of patient 1 , the total DNA was extracted from the peripheral blood leukocytes and the frozen muscle specimens using the DNeasy Blood \& Tissue kit (Qiagen). MitoChip v2.0 (The GeneChip ${ }^{\circledR}$ Human Mitochondrial Resequencing Array 2.0), which provides a standard assay for the complete sequence analysis of human mitochondrial DNA, was obtained from Affymetrix. The patient's entire mitochondrial DNA was sequenced using MitoChip v2.0 as previously described [37]. Analysis of the microarray data obtained with MitoChip v2.0 was performed using GeneChip Sequence Analysis Software v4.0 (Affymetrix) [24].

In order to reveal the mutations that were confirmed by MitoChip v2.0, a 465-base pair PCR product that spanned all of the mutation sites was screened by DNA sequencing. In brief, $50 \mathrm{ng}$ of the patient's genomic DNA was amplified using the hot-start PCR method and a forward
(5'-CACCATTCTCCGTGAAATCA-3') and reverse primer (5'-AGGCTAAGCGTTTTGAGCTG-3') [5, 29]. Each PCR product was generated under the following conditions: $15 \mathrm{~min}$ at $95^{\circ} \mathrm{C}, 42$ cycles of amplification $\left(95^{\circ} \mathrm{C}\right.$ for $30 \mathrm{~s}, 61^{\circ} \mathrm{C}$ for $30 \mathrm{~s}$, and $72^{\circ} \mathrm{C}$ for $1 \mathrm{~min}$ ), and $30 \mathrm{~min}$ at $72^{\circ} \mathrm{C}$. Using a presequencing kit (USB, Cleveland, $\mathrm{OH}$, USA), the patient's PCR products with abnormal elution profiles were purified, and the appropriate PCR products from relatives and control chromosomes were obtained and sequenced by dye-terminator chemistry using an ABI Prism 377 sequencer (Applied Biosystems, Foster City, CA, USA). The resulting sequences were then aligned and any mutations were evaluated using the Sequencher sequence alignment program (Gene Codes, Ann Arbor, MI, USA).

The polymorphic and pathogenic natures of the confirmed mutations were checked against two databases: the MITOMAP (http://www.mitomap.org/) and GiiB-JST mtSNP database (http://mtsnp.tmig.or.jp/mtsnp/index.shtml).

\section{Results}

Histological and immunohistochemical characterizations

The muscle fibers ranged from 10 to $80 \mu \mathrm{m}$ in diameter. Sixty-nine of the 609 Gomori trichrome stained muscle fibers $(11.3 \%)$ were ragged-red fibers (Fig. 3a). Cytochrome $c$ oxidase (COX) activity was deficient in many of the ragged-blue fibers that were stained with succinate dehydrogenase (SDH) and COX (233 of 881 muscle fibers, $26.4 \%$ ) (Fig. 3b, c), and no blood vessels showing strong $\mathrm{SDH}$ reactivity were observed. In NADH dehydrogenasereactive sections, focal decreases and increases in oxidative enzyme activities were observed. Adenosine monophosphate (AMP) deaminase activity was normal. The random checkerboard distribution of the histochemical fiber types was preserved as shown in the ATPase-reactive sections. Acid phosphatase activity was slightly high in some fibers. Muscle fiber glycogen contents appeared normal and the lipid contents were slightly high in some fibers. Electron microscopy showed abnormal proliferation of mitochondria with paracrystalline inclusions (Fig. 4).

Biochemical studies

All respiratory chain enzyme activities, which are expressed as a percentage of the normal control values relative to the citrate synthase activity, were greater than $20 \%$ (Table 1). BN-PAGE revealed no abnormalities in either the respiratory chain complexes or their molecular assembly structures. 

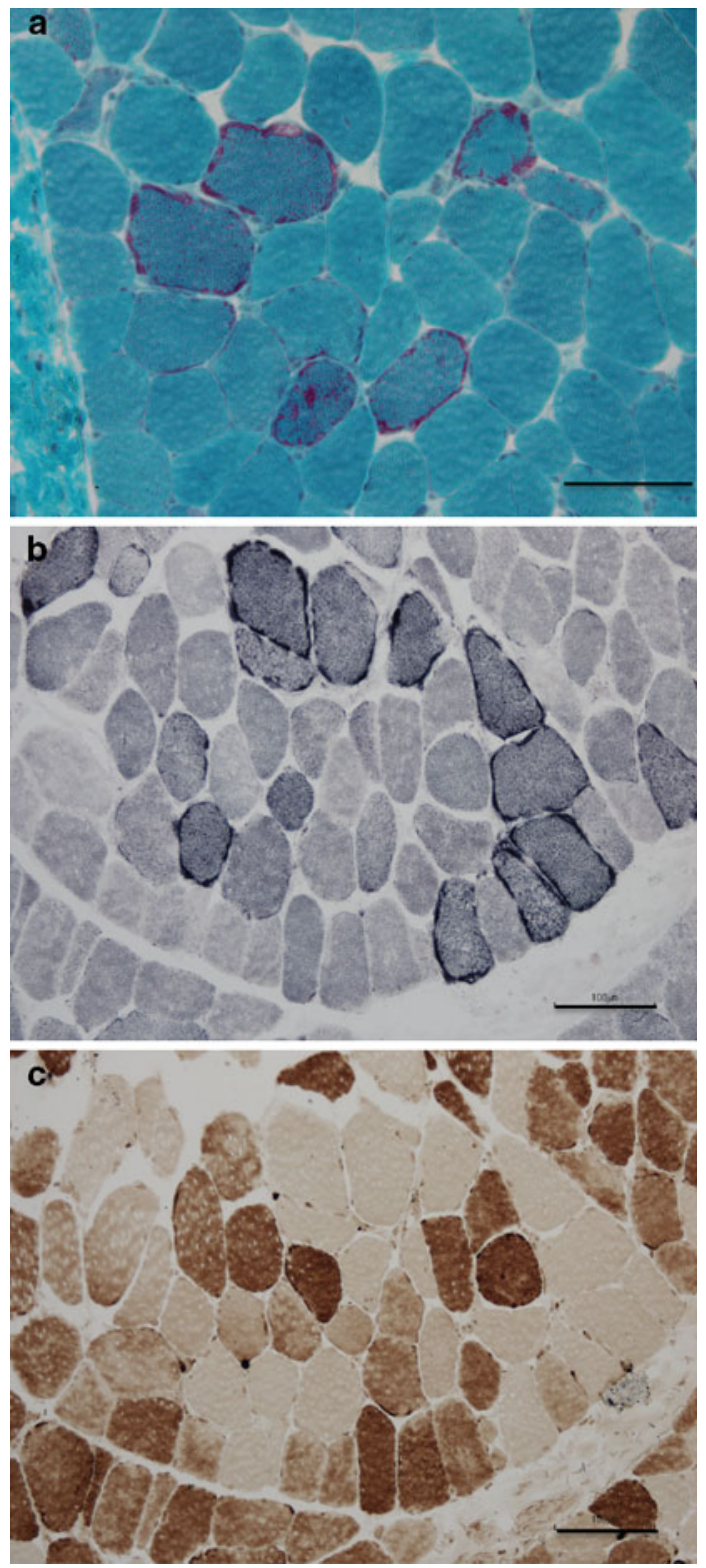

Fig. 3 Histochemical analysis of the right biceps brachii muscle. a Gomori trichrome staining reveals typical ragged-red fibers. Histochemical analysis of serial sections of samples stained with b SDH or c COX shows a number of ragged-blue fibers with $\mathrm{COX}$ deficiency. a-c Bar $100 \mu \mathrm{m}$

\section{Mitochondrial DNA analysis}

Using MitoChip v2.0, 37 missense variants were detected in the mitochondrial DNA of the peripheral blood lymphocytes. All of these variants show polymorphisms and are listed in the MITOMAP and GiiB-JST mtSNP databases. Two additional missense variants were detected in the mitochondrial DNA of the muscle homogenate; the variants were $\mathrm{m} \cdot 602 \mathrm{C}>\mathrm{T}$ in the $\mathrm{tRNA}^{\mathrm{Phe}}$ gene and $\mathrm{m} .16111 \mathrm{C}>\mathrm{G}$ in the D-loop. The variant $\mathrm{m} .16111 \mathrm{C}>\mathrm{G}$ is listed as a polymorphism, but the variant $\mathrm{m} .602 \mathrm{C}>\mathrm{T}$ is not
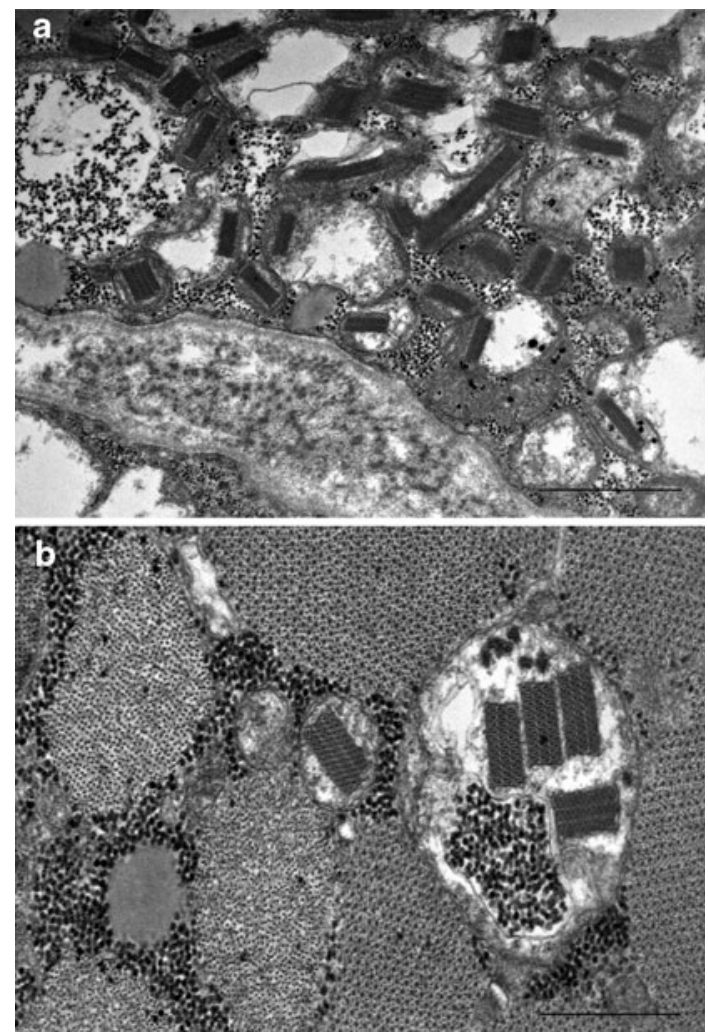

Fig. 4 Electron micrograph of abnormal mitochondria in the right biceps brachii muscle. Abnormal mitochondria with paracrystalline inclusions that are suggestive of mitochondrial myopathy are shown. a bar $1 \mu \mathrm{m}$, b bar $500 \mathrm{~nm}$

reported in either database. The $\mathrm{m} .602 \mathrm{C}>\mathrm{T}$ variant was also confirmed by direct sequencing. The sequence chromatogram showed a heteroplasmic $\mathrm{m} .602 \mathrm{C}>\mathrm{T}$ transition in the muscle homogenate mitochondrial $\mathrm{tRNA}^{\text {Phe }}$ gene (Fig. 5a). The proportion of mutant mitochondrial DNA in the muscle was $64.7 \pm 1.2 \%$ (mean $\pm \mathrm{SD}$; the operation was performed thrice). Mutant mitochondrial DNA was not detected in the blood lymphocytes when measured using real-time amplification refractory mutation system quantitative PCR analysis (RT-ARMS qPCR), as previously described $[2,10]$. Healthy Japanese controls $(n=100)$ did not show these mutations in their blood lymphocytes, at least not within the limits of Sanger's method for DNA sequencing.

\section{Discussion}

A novel mitochondrial tRNA ${ }^{\text {Phe }}$ gene mutation was identified in a patient with late-onset predominant axial myopathy and cerebellar ataxia (patient 1 ). She presented with a maternal history of bent spine, and her elder sister presented with elevated lactate levels, severe paraspinal muscle atrophy, and epilepsy. Furthermore, the sister's four 
Table 1 Enzymatic activities for mitochondrial respiratory complexes in patient 1

\begin{tabular}{llllll}
\hline & CI activity (CI/CS) & CII activity (CII/CS) & CIII activity (CIII/CS) & CIV activity (CIV/CS) & CS activity \\
\hline Patient 1 & $0.1938(0.7027)$ & $0.2723(0.9874)$ & $1.2737(4.6192)$ & $0.0579(0.21)$ & 0.2757 \\
Control & $0.3194(1.6183)$ & $0.2751(1.3444)$ & $1.3132(6.5512)$ & $0.0826(0.3840)$ & 0.2151 \\
Patient 1/control ratio & $60.7 \%(43.4 \%)$ & $98.9 \%(73.4 \%)$ & $97.0 \%(70.5 \%)$ & $70.1 \%(54.7 \%)$ \\
\hline
\end{tabular}

Enzymatic activities for individual mitochondrial respiratory complexes are given in $\mathrm{nmol} / \mathrm{min}$ protein, and represent percentage of normal control $(n=10)$ mean relative to a reference enzyme of citrate synthase (CS)

The activities are relatively low in complex I and complex IV compared with other complexes

CI complex I, CII complex II, CIII complex III, CIV complex IV

a

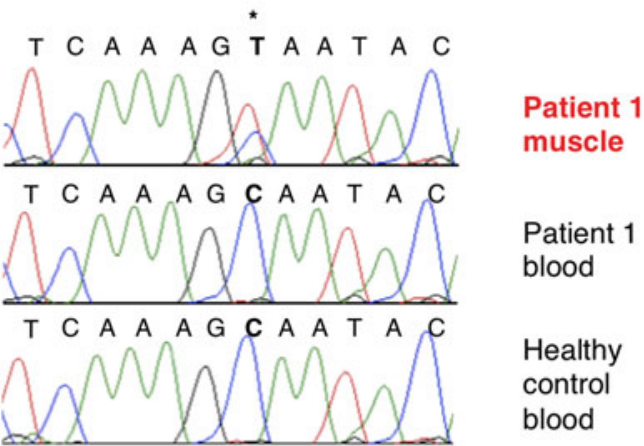

C

\begin{tabular}{|c|c|c|}
\hline Hom & G & $\mathrm{C} T \mathrm{~T}$ A C C T C C T C $-A$ A A G \\
\hline Patient 1 & G & $C T T A C C T C C T C-A A A G T$ \\
\hline Rattus & G & $C T T A-T A A T-A A A G C$ \\
\hline Meles & G & $-T A A=T-A A A G$ \\
\hline Eulemur & G & $C T$ T A A A C C A C T - A A A G C \\
\hline Tomistoma & G & $C T T A A A T A C T-A A A G C$ \\
\hline husa & A & $T \mathrm{~T} T \mathrm{~T}$ T $\mathrm{T}$ A $\mathrm{T} \cdots \mathrm{A}$ G A A $\mathrm{A}$ \\
\hline Calliptamus & G & $C T T A T A T T T A \cdots G A G C$ \\
\hline Epigonichthys & & $G T T A A G C \cdots A$ G A C \\
\hline Aspid & & $\mathrm{C} T \mathrm{~T}$ A T A T T T A $\cdots \mathrm{GA}$ \\
\hline & & $C T T A A C C T G G T T A G A G$ \\
\hline Echinoce & & $T A A A T T$ \\
\hline
\end{tabular}

b

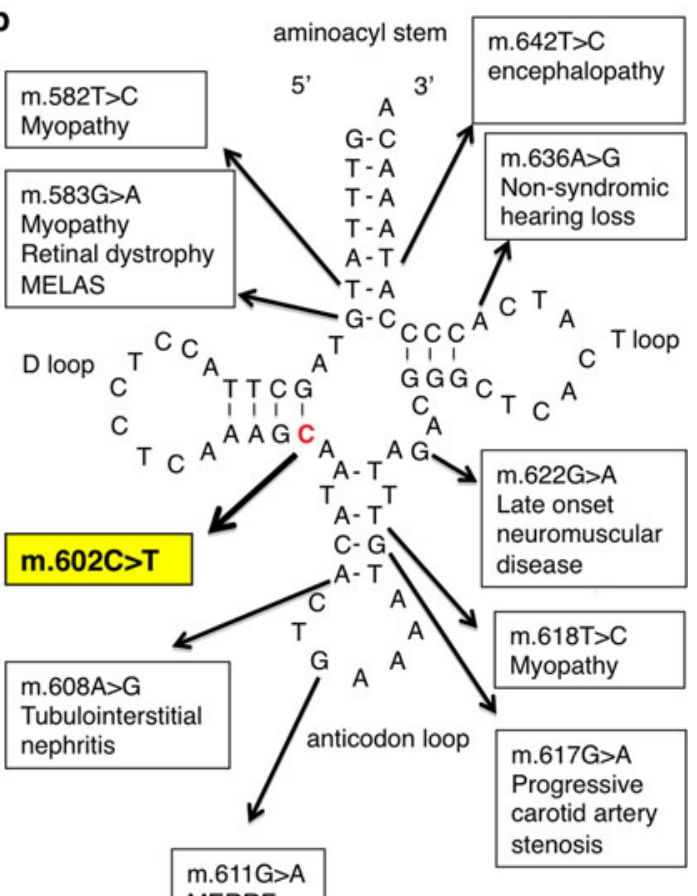

Fig. 5 a Sequence chromatogram of the mitochondrial DNA region that encompasses the $\mathrm{m} \cdot 602 \mathrm{C}>\mathrm{T}$ alteration (asterisk) that was obtained from the skeletal muscle of patient 1 (reverse complement). b Schematic diagram of the mitochondrial tRNA ${ }^{\text {Phe }}$ cloverleaf

sons presented with elevated CK levels, among which one had epilepsy. Patient 1 also presented with other symptoms associated with mitochondrial disease, including mild blepharoptosis, cataracts, hearing loss, and arrhythmia. Morphological examination revealed many ragged-red fibers and a partial deficiency in COX activity. One of the major diagnostic criteria for respiratory chain disorders in adults is less than $20 \%$ activity in any of the tissue complexes, but the data of the present study did not fulfill this condition [4]. However, the activities of complexes I $(43.4 \%)$ and IV $(54.7 \%)$ were lower than those of the other complexes. The decreased activities of complexes I and IV are probably due to the deficiency in COX activity that was structure showing previously reported mutations and the $\mathrm{m} .602 \mathrm{C}>\mathrm{T}$ alteration in the D-stem. c Comparison of mitochondrial tRNA ${ }^{\text {Phe }}$ from different species. Base pairs, including the 602 nucleotides, are shown in boxes

measured in the muscle fibers. These clinical, morphological, and biochemical manifestations indicate that the patient most likely had a mitochondrial disease.

The marked atrophy of the paraspinal muscles was the most interesting feature found in patients 1 and 2. Axial myopathy has been defined as muscle weakness that is limited to the spinal and neck muscles [21]. Therefore, the symptoms of patient 1 are incompatible with pure axial myopathy because of the muscle weakness and mitochondrial abnormalities that were observed in the biceps brachii muscle. The most characteristic feature of axial myopathy is the remarkable atrophy of the paraspinal muscles rather than the atrophy of the muscles of the limbs, which is 
different from the clinical symptoms of conventional mitochondrial myopathy. Thus, based on the available evidence, we believe that patients 1 and 2 can be diagnosed with mitochondrial predominant axial myopathy.

Axial myopathy may occur secondary to various diseases. However, only five cases of mitochondrial axial myopathy associated with the prominent involvement of the extensor muscles of the spine have been previously reported (Table 2) [8, 11, 28, 30, 32]. All these cases presented with abnormal trunk flexion that developed during walking and disappeared when the patient was in a supine position. In the cases described here, only patient 2 presented with camptocormia. These common symptoms, including late-onset, mildly elevated serum CK levels, ragged-red fibers, and the partial deficiency in COX activities, were observed in patient 1 and also in the above mentioned cases. However, biochemical analysis was performed in only one case that showed deficiencies in complexes I and III [32]. No case has been previously reported that describes a family history of similar symptoms. In addition, no genetic cause of any mitochondrial axial myopathy has been previously reported.

This study is unable to conclusively prove or disprove the pathogenicity of the m.602C $>\mathrm{T}$ mutation. However, three reasons that support the pathogenicity of this mutation are apparent. First, the heteroplasmic m.602C $>\mathrm{T}$ point mutation disrupts a conserved Watson-Crick cytosineguanine $(\mathrm{C}-\mathrm{G})$ base pairing within the D-stem of the mitochondrial tRNA ${ }^{\text {Phe }}$ gene, which would most likely affect the stability of the secondary structure of mitochondrial tRNA (Fig. 5b). Almost 94\% of mitochondrial tRNA pathogenic mutations occur in this stem structure, and the disruption of Watson-Crick $\mathrm{C}-\mathrm{G}$ base pairing is a significantly more common feature of pathogenic mutations than neutral variants [23]. Second, after performing a sequence homology search using CLUSTALW (http://clustalw. ddbj.nig.ac.jp/top-j.html), it was determined that this base pairing is largely conserved in other species as $\mathrm{C}-\mathrm{G}$ or adenine-thymine base pairings (Fig. 5c). Third, the mutation is heteroplasmic and present in the affected skeletal muscles but not in the peripheral blood lymphocytes. Almost all pathogenic mitochondrial tRNA mutations in clinically affected tissues have a high proportion of heteroplasmy compared with unaffected tissues [23].

However, the decreased activities of complexes I and IV that were observed during the biochemical examination cannot be completely explained by the disruption in mitochondrial protein synthesis that could have been caused by the mitochondrial tRNA mutation. In addition, data obtained from the single muscle fiber analyses were limited due to the small sample size, and therefore, are not sufficient to prove the pathogenicity of the m.602C $>\mathrm{T}$ mutation.

Any additional evidence of the pathogenicity of the cybrid cells was not obtained. Therefore, 10 points (out of a maximum score of 20 points) was applied to the scoring criteria of the mitochondrial tRNA mutations listed in MITOMAP, which indicated that the m.602C $>$ T mutation is possibly pathogenic [23].

The mechanism of late-onset axial myopathy induced by mitochondrial dysfunction is unclear. Nine pathogenic mutations in the mitochondrial tRNA ${ }^{\text {Phe }}$ gene have been previously described in various diseases (Fig. 5b), including a late-onset neuromuscular disease but not axial myopathy [7, 9, 12, 14, 17, 18, 22, 25, 34, 35]. A probable etiological mechanism for the presentation of such a myopathy in the elderly is the accumulation of mitochondrial tRNA pathogenic mutations that affect aging tissues [9]. If it is possible to get any information on the pathological status of the primarily affected muscles, this would perhaps be as informative as the differential involvement of the biceps and paraspinal muscles. Unfortunately, these data could not be obtained due to the remarkable fatty degeneration of the paraspinal muscles.

The patients described in this report are characterized by the combination of axial myopathy and CNS involvement. One report about a parkinsonian patient with mitochondrial axial myopathy suggested that mitochondrial dysfunction

Table 2 Clinical characteristics of patients with paraspinal muscle atrophy from mitochondrial myopathy

\begin{tabular}{llllllll}
\hline Age/sex [Ref.] & Onset age & Family history & CK (IU/l) & RRF & COX deficiency & mtDNA mutation & Neurological deficit \\
\hline 73/F [patient 1] & 63 & + & 290 & + & + & $602 C>$ T & Cerebellar ataxia \\
84/F [patient 2] & 60 & + & 474 & NE & NE & NE & Encephalopathy \\
65/M [32] & 59 & - & 245 & + & + & NR & - \\
65/M [30] & 62 & NR & NR & + & + & NR & Parkinsonism \\
78/M [11] & 78 & NR & 501 & + & + & NR & - \\
64/M [28] & NR & NR & Elevated & + & + & NR & - \\
55/M [8] & NR & NR & Normal & + & + & NR & -
\end{tabular}

$M$ male, $F$ female, $C K$ creatine kinase, $R R F$ ragged-red fiber, $N R$ not reported, $N E$ not evaluated, $C O X$ cytochrome $c$ oxidase, $m t D N A$ mitochondrial DNA, Ref reference 
may lead to both axial myopathy and parkinsonism [30]. In the patients described here, CNS involvement was similar to that observed in myoclonus epilepsy with ragged-red fiber (MERRF) due to the accompanying cerebellar atrophy and epilepsy. In fact, MERRF has been previously reported to be associated with pathogenic mutations of the mitochondrial tRNA ${ }^{\text {Phe }}$ gene [22].

Finally, mitochondrial dysfunction might be implicated in the development of Hashimoto thyroiditis in patients 1 and 2 and in the fourth son of patient 2; the relationship between mitochondrial diseases and Hashimoto thyroiditis has been previously described [3, 20, 26, 27].

In summary, this is the first report about familial mitochondrial disease with late-onset predominant axial myopathy and encephalopathy, which were confirmed by clinical and histological findings. This case expands the phenotypic spectrum of mitochondrial diseases. Future studies on the novel mitochondrial tRNA $^{\text {Phe }} 602 \mathrm{C}>\mathrm{T}$ mutation may contribute to the understanding of late-onset predominant axial myopathy and encephalopathy.

Acknowledgments We wish to thank Dr. A. Sano and Dr. M. Nakamura for performing the quantitative PCR studies. We also wish to thank Ms. A. Yoshimura, Ms. N. Hirata, Ms. Y. Shirahama, and Ms. M. Ishigami for their excellent technical assistance. This study was supported in part by grants from the Nervous and Mental Disorders and Research Committee for Ataxic Disease of the Japanese Ministry of Health, Welfare and Labor (grant 19A-1, H.T.) and the Ministry of Education, Culture, Sports, Science and Technology of Japan (grant 21591095, H.T.; 21591094, I. H.).

Open Access This article is distributed under the terms of the Creative Commons Attribution Noncommercial License which permits any noncommercial use, distribution, and reproduction in any medium, provided the original author(s) and source are credited.

\section{References}

1. Azher SN, Jankovic J (2005) Camptocormia: pathogenesis, classification, and response to therapy. Neurology 65:355-359

2. Bai RK, Wong LJ (2004) Detection and quantification of heteroplasmic mutant mitochondrial DNA by real-time amplification refractory mutation system quantitative PCR analysis: a singlestep approach. Clin Chem 50:996-1001

3. Berio A, Piazzi A (2002) A case of Kearns-Sayre syndrome with autoimmune thyroiditis and possible Hashimoto encephalopathy. Panminerva Med 44:265-269

4. Bernier FP, Boneh A, Dennett X, Chow CW, Cleary MA, Thorburn DR (2002) Diagnostic criteria for respiratory chain disorders in adults and children. Neurology 59:1406-1411

5. Boerkoel CF, Takashima H, Stankiewicz P et al (2001) Periaxin mutations cause recessive Dejerine-Sottas neuropathy. Am J Hum Genet 68:325-333

6. D'Aurelio M, Gajewski CD, Lenaz G, Manfredi G (2006) Respiratory chain supercomplexes set the threshold for respiration defects in human mtDNA mutant cybrids. Hum Mol Genet $15: 2157-2169$
7. Darin N, Kollberg G, Moslemi AR et al (2006) Mitochondrial myopathy with exercise intolerance and retinal dystrophy in a sporadic patient with a G583A mutation in the mt tRNA(phe) gene. Neuromuscul Disord 16:504-506

8. Delcey V, Hachulla E, Michon-Pasturel U et al (2002) Camptocormia: a sign of axial myopathy. Report of 7 cases. Rev Med Interne 23:144-154

9. Deschauer M, Swalwell H, Strauss M, Zierz S, Taylor RW (2006) Novel mitochondrial transfer RNA(Phe) gene mutation associated with late-onset neuromuscular disease. Arch Neurol 63:902-905

10. Genasetti A, Valentino ML, Carelli V et al (2007) Assessing heteroplasmic load in Leber's hereditary optic neuropathy mutation 3460G->A/MT-ND1 with a real-time PCR quantitative approach. J Mol Diagn 9:538-545

11. Gomez-Puerta JA, Peris P, Grau JM, Martinez MA, Guanabens N (2007) Camptocormia as a clinical manifestation of mitochondrial myopathy. Clin Rheumatol 26:1017-1019

12. Hanna MG, Nelson IP, Morgan-Hughes JA, Wood NW (1998) MELAS: a new disease associated mitochondrial DNA mutation and evidence for further genetic heterogeneity. J Neurol Neurosurg Psychiatry 65:512-517

13. Higuchi I, Niiyama T, Uchida Y et al (1999) Multiple episodes of thrombosis in a patient with Becker muscular dystrophy with marked expression of utrophin on the muscle cell membrane. Acta Neuropathol 98:313-316

14. Iizuka T, Goto Y, Miyakawa S et al (2009) Progressive carotid artery stenosis with a novel tRNA phenylalanine mitochondrial DNA mutation. J Neurol Sci 278:35-40

15. Jungbluth $\mathrm{H}$, Lillis $\mathrm{S}$, Zhou $\mathrm{H}$ et al (2009) Late-onset axial myopathy with cores due to a novel heterozygous dominant mutation in the skeletal muscle ryanodine receptor (RYR1) gene. Neuromuscul Disord 19:344-347

16. Karbowski K (1999) The old and the new camptocormia. Spine (Phila Pa 1976) 24:1494-1498

17. Kleinle S, Schneider V, Moosmann P, Brandner S, Krahenbuhl S, Liechti-Gallati S (1998) A novel mitochondrial tRNA(Phe) mutation inhibiting anticodon stem formation associated with a muscle disease. Biochem Biophys Res Commun 247:112-115

18. Konings A, Van Camp G, Goethals A et al (2008) Mutation analysis of mitochondrial DNA 12SrRNA and tRNASer(UCN) genes in non-syndromic hearing loss patients. Mitochondrion $8: 377-382$

19. Kottlors M, Kress W, Meng G, Glocker FX (2010) Facioscapulohumeral muscular dystrophy presenting with isolated axial myopathy and bent spine syndrome. Muscle Nerve 42:273-275

20. Kovacs GG, Hoftberger R, Majtenyi K et al (2005) Neuropathology of white matter disease in Leber's hereditary optic neuropathy. Brain 128:35-41

21. Mahjneh I, Marconi G, Paetau A, Saarinen A, Salmi T, Somer H (2002) Axial myopathy-an unrecognised entity. J Neurol 249:730-734

22. Mancuso M, Filosto M, Mootha VK et al (2004) A novel mitochondrial tRNAPhe mutation causes MERRF syndrome. Neurology 62:2119-2121

23. McFarland R, Elson JL, Taylor RW, Howell N, Turnbull DM (2004) Assigning pathogenicity to mitochondrial tRNA mutations: when "definitely maybe" is not good enough. Trends Genet 20:591-596

24. Mithani SK, Smith IM, Zhou S et al (2007) Mitochondrial resequencing arrays detect tumor-specific mutations in salivary rinses of patients with head and neck cancer. Clin Cancer Res 13:7335-7340

25. Moslemi AR, Lindberg C, Toft J, Holme E, Kollberg G, Oldfors A (2004) A novel mutation in the mitochondrial tRNA(Phe) gene 
associated with mitochondrial myopathy. Neuromuscul Disord 14:46-50

26. Muller-Hocker J, Jacob U, Seibel P (1998) Hashimoto thyroiditis is associated with defects of cytochrome- $c$ oxidase in oxyphil Askanazy cells and with the common deletion $(4,977)$ of mitochondrial DNA. Ultrastruct Pathol 22:91-100

27. Ohno K, Yamamoto M, Engel AG et al (1996) MELAS- and Kearns-Sayre-type co-mutation [corrected] with myopathy and autoimmune polyendocrinopathy. Ann Neurol 39:761-766

28. Poullin P, Daumen-Legre V, Serratrice G (1993) Camptocormia in the elderly patient: myopathy or muscular dystonia? Rev Rhum Ed Fr 60:159-161

29. Rieder MJ, Taylor SL, Tobe VO, Nickerson DA (1998) Automating the identification of DNA variations using quality-based fluorescence re-sequencing: analysis of the human mitochondrial genome. Nucleic Acids Res 26:967-973

30. Schabitz WR, Glatz K, Schuhan C et al (2003) Severe forward flexion of the trunk in Parkinson's disease: focal myopathy of the paraspinal muscles mimicking camptocormia. Mov Disord $18: 408-414$
31. Serratrice G (2007) Axial myopathies: an elderly disorder. Acta Myol 26:11-13

32. Serratrice G, Pouget J, Pellissier JF (1996) Bent spine syndrome. J Neurol Neurosurg Psychiatry 60:51-54

33. Trounce IA, Kim YL, Jun AS, Wallace DC (1996) Assessment of mitochondrial oxidative phosphorylation in patient muscle biopsies, lymphoblasts, and transmitochondrial cell lines. Methods Enzymol 264:484-509

34. Tzen CY, Tsai JD, Wu TY et al (2001) Tubulointerstitial nephritis associated with a novel mitochondrial point mutation. Kidney Int 59:846-854

35. Valente L, Piga D, Lamantea E et al (2009) Identification of novel mutations in five patients with mitochondrial encephalomyopathy. Biochim Biophys Acta 1787:491-501

36. Wittig I, Braun HP, Schagger H (2006) Blue native PAGE. Nat Protoc 1:418-428

37. Zhou S, Kassauei K, Cutler DJ et al (2006) An oligonucleotide microarray for high-throughput sequencing of the mitochondrial genome. J Mol Diagn 8:476-482 